\title{
Práticas de leitura no ensino de Língua Portuguesa em Timor-Leste: um estudo exploratório
}

\author{
Renata Tironi Camargo* \\ Joice Eloi Guimarães**
}

Resumo

Este trabalho apresenta uma discussão sobre as práticas de leitura no ensino de língua portuguesa em Timor-Leste. Desde 2002, o português figura, juntamente com a língua tétum, como língua oficial e de instrução nesse país. A partir de então, professores e alunos timorenses lidam com dificuldades relacionadas ao ensino e à aprendizagem dessa língua nas escolas, as quais são advindas de fatores decorrentes da constituição sóciohistórica do país, dentre os quais destacamos embates políticolinguísticos, recursos humanos e estruturais escassos e carência de formação específica em ensino de português língua não materna. A partir desse contexto, a proposta deste trabalho é identificar e compreender estratégias relacionadas à leitura em língua portuguesa que professores timorenses valoram positivamente nas salas de aula de Timor-Leste. Para tanto, aplicamos um questionário a docentes atuantes no ensino básico e analisamos os dados gerados com base na teoria do dialogismo de Bakhtin e seu Círculo. De forma geral, a análise realizada apontou que a valorização da prática da leitura em português nas salas de aula de Timor-Leste está imbricada na relação historicamente estabelecida no país entre a língua portuguesa e a palavra escrita. No campo metodológico, aquilo que os professores valoram positivamente recai ora sobre práticas

\footnotetext{
* Universidade Federal de São Carlos (UFSCar). Doutoranda em Linguística pela Universidade Federal de São Carlos. O presente trabalho foi realizado com apoio da Coordenação de Aperfeiçoamento de Pessoal de Nível Superior - Brasil (CAPES) - Código de Financiamento 001.ORCID: https://orcid.org/0000-0002-5303-834X.

** Hankuk University of Foreign Studies. Doutora em Linguística Aplicada pela Universidade Estadual de Campinas. Professora da Hankuk University of Foreign Studies. ORCID: https://orcid.org/0000-0002-2044-400X.
} 
tradicionalmente utilizadas no ensino da leitura, ora sobre práticas sensíveis ao contexto de ensino de português como língua não materna e que levam em conta o diálogo entre textos.

Palavras-chave: Práticas de leitura. Língua portuguesa. TimorLeste. Dialogismo.

\title{
Reading practices in Portuguese language teaching in East Timor: an exploratory study
}

\begin{abstract}
This paper presents a discussion on reading practices in Portuguese language teaching in East Timor. Since 2002, Portuguese appears, along with the Tetun language, as the official and instructional language in that country. Since then, Timorese teachers and students have dealt with difficulties related to the process of teaching and learning Portuguese in schools and these obstacles are due to some factors arising from the country's socio-historical constitution, such as language policy problems, scarce human and structural resources, lack of specific education in teaching Portuguese as a non-native language, among others. From this context, the purpose of this paper is to identify and comprehend the strategies related to reading in Portuguese that Timorese teachers appraise positively in the classrooms of East Timor. To this end, we applied a questionnaire to teachers working in basic education and analyzed the data generated based on Dialogic Theory of Bakhtin's Circle. In general, the analysis showed that the appreciation of the practice of reading in Portuguese in the classrooms of East Timor is related to the relationship historically established in the country between the Portuguese language and the written word. In the methodological field,
\end{abstract}


what teachers appraise positively lies on practices traditionally used in the teaching of reading, and on practices that are sensitive to the context of teaching Portuguese as a non-native language and that consider the dialogue between texts.

Keywords: Reading practices. Portuguese language. East Timor. Dialogic theory.

Recebido em: 07/03/2021 // Aceito em: 20/04/2021. 


\section{Introdução}

Após muitos conflitos, no ano de 2002, a Língua Portuguesa (LP) foi estabelecida como língua oficial e de instrução em Timor-Leste, junto à língua tétum, que abriga o maior número de falantes no país. Essa decisão fez surgir uma série de impasses, principalmente nos ambientes escolares. No que diz respeito à prática de leitura em língua portuguesa, professores e alunos timorenses encaram diariamente inúmeras dificuldades, como aquelas decorrentes do fato de o português não ser a língua utilizada pela maioria da população, possuidora de diferentes línguas maternas, que são tradicionalmente orais. Além disso, o histórico de Timor deixa à mostra não só o escasso incentivo à leitura, como também ações que inviabilizaram o estabelecimento de uma cultura leitora nesse país.

Tendo em vista esse contexto, nosso objetivo, neste trabalho, é identificar e compreender quais estratégias relacionadas à leitura em LP os professores timorenses valoram positivamente no desenvolvimento de sua prática pedagógica. Para tanto, aplicamos um questionário on-line a docentes atuantes no ensino básico de Timor-Leste, licenciados no curso de Formação de Professores do Ensino Básico da Universidade Nacional Timor Lorosa'e (UNTL). Os enunciados expressos pelo questionário são foco de nossa análise, a qual é realizada com base na teoria do dialogismo desenvolvida por Bakhtin e integrantes do grupo posteriormente denominado de Círculo de Bakhtin.

Para a consecução do objetivo aqui traçado, este trabalho está organizado da seguinte maneira: primeiramente, descrevemos o percurso da LP em Timor-Leste e discutimos questões que levaram a certa hierarquização linguística no país. Em seguida, 
traçamos um panorama histórico sobre a presença da palavra escrita em Timor-Leste e abordamos o tema do componente leitura nas prescrições voltadas ao sistema educacional. Após, apresentamos a teoria do dialogismo na qual esta pesquisa se fundamenta. Descrevemos, então, a metodologia utilizada neste trabalho, os participantes e o instrumento de geração dos dados, os quais são alvo de análise na seção seguinte. Por fim, apresentamos algumas considerações sobre esta pesquisa.

\section{Língua portuguesa em Timor-Leste}

A LP está presente em Timor-Leste desde o século XVI, época em que fora trazida por portugueses que se instalaram nesse território; entretanto, sua disseminação não era uma prioridade naquela época. Assim, em suas comunicações cotidianas, os timorenses faziam uso das línguas autóctones do país, enquanto o uso da LP se restringia à escrita ou às atividades relativas a determinados fins de ordem cultural ou administrativa (BRITO, 2010). A opção pelo português como "língua da escrita" em Timor-Leste nesse período resulta, em grande medida, da hierarquização linguística construída na relação colonizador $\mathrm{x}$ colonizado - em que a língua daquele é revestida de poder e relacionada à racionalidade, enquanto as línguas originalmente do território colonizado, fundamentalmente de base oral, são consideradas inferiores por não possuírem um sistema de escrita estabilizado e capaz de suprir as exigências do modelo organizacional agora imposto.

Acontecimento que deu novos rumos ao contexto linguístico timorense foi a invasão empreendida pela Indonésia, em 1975. A presença indonésia em Timor foi marcada pela 
imposição, de forma violenta, da política, cultura e língua do país dominador. Para tanto, foi proibida a utilização do português e restringido o uso do tétum ${ }^{1} \mathrm{e}$ das demais línguas autóctones. $\mathrm{Na}$ esfera educacional, o idioma e o sistema de ensino português foram rapidamente banidos e substituídos pelos indonésios.

Ao longo da ocupação indonésia, milhares de timorenses morreram. A rejeição ao regime imposto pelo país dominador deu início a um movimento de luta pela libertação nacional. Liderado por uma elite - pequena parcela da população composta de mestiços, políticos, funcionários públicos, professores etc. esse movimento de resistência timorense à invasão indonésia elegeu a LP como um dos símbolos dessa luta. Isso explica, em parte, a opção pelo português como língua oficial e de instrução, junto à língua tétum, no momento da Restauração da Independência da República Democrática de Timor-Leste, em 2002.

É importante destacar que o período de transição, do governo indonésio para o governo de Timor Independente, teve início de forma violenta e deixou marcas que repercutem até hoje em vários setores da sociedade timorense. Antes de deixarem o país, os militares indonésios, com auxílio de milícias timorenses pró-Indonésia, causaram mortes e muita destruição: casas e prédios públicos foram queimados e, em relação à infraestrutura educacional, $90 \%$ das escolas foram parcial ou totalmente danificadas (CARVALHO, 2007).

$\overline{1}$ A variedade tétum praça, falada sobretudo na capital do país, Díli, alcançou o status de língua franca da evangelização no período de domínio indonésio, quando o português foi proibido, o que the conferiu um prestígio até então não alcançado por nenhuma língua autóctone em Timor-Leste, o de língua dos batizados (HULL, 2002). No entanto, é importante mencionar a existência de outras variedades da língua tétum no território timorense, nomeadamente o Tétum Térik e o Tétum Belo.(HULL; ECCLES, 2001 apud ALBUQUERQUE, 2011). Ao longo deste texto, no qual utilizamos apenas "tétum", nos referimos à variedade tétum praça, que é a presente nos documentos oficiais e objeto de estudo e sistematização gramatical, como, por exemplo, aquela desenvolvida pelo Instituto Nacional de Linguística de Timor-Leste (Decreto-Lei no 1/2004, que institui "O Padrão Ortográfico da Língua Tétum”). 
Atualmente, Timor-Leste contempla, em sua Constituição, a multiplicidade linguística presente no país, a qual foi, durante o domínio indonésio, cerceada em prol do projeto político de estado do país invasor. Dessa forma, estão presentes, nesse documento, as línguas nacionais, ${ }^{2}$ as línguas de trabalho, o inglês e a língua indonésia, além das línguas oficiais e de instrução, o tétum e o português. O tétum é a língua veicular utilizada entre os timorenses possuidores de diferentes línguas maternas. ${ }^{3}$ Como as demais línguas nacionais, constitui-se como uma língua fundamentalmente de tradição oral. A padronização de uma norma ortográfica do tétum teve início apenas em 2003, com a fundação do Instituto Nacional de Linguística de TimorLeste.

De acordo com o pesquisador timorense Paulino (2013, p. 105), "nas sociedades de tradição oral - como no caso da sociedade timorense - as palavras estão associadas directamente a ocorrências, eventos e acontecimentos." Ou seja, os registros da memória do povo timorense são feitos, principalmente, pela modalidade oral da língua.

Essa característica, associada ao percurso histórico aqui já relatado - a escassez de incentivo português à educação em Timor durante a colonização e a destruição dos prédios públicos ao fim da invasão indonésia, os quais guardavam registros escritos da história do país, e também o escasso acervo de livros - explica, em parte, a relação, por vezes distante, de muitos timorenses com a palavra escrita.

\footnotetext{
2 Não há um consenso em relação ao número exato de línguas nacionais presentes em Timor-Leste, entretanto, comumente, autores concordam com um número entre 20 e 30 línguas.

3 O tétum, apesar de não ser falado em todo o território de Timor-Leste, é amplamente empregado para mediar as interações entre timorenses provenientes de diferentes localidades do país.
} 


\section{Hierarquização linguística e letramento}

A característica oral das línguas autóctones de TimorLeste está entre os fatores que, historicamente, atribuíam à LP o lugar de língua da escrita nessa sociedade. Por conta disso, no campo do ensino, observa-se que, atualmente, as línguas timorenses adquirem o lugar de línguas auxiliares no processo de aprendizagem do português. Assim, vemos que a hierarquização linguística historicamente presente no cenário timorense que tem sua origem no processo colonizatório - endossa, nos ambientes de ensino, a dicotomia da escrita versus oralidade.

$\mathrm{O}$ entendimento de que oralidade e escrita são práticas apartadas remete à concepção presente no modelo autônomo de letramento (STREET, 1984). Esse modelo privilegia determinados tipos de letramento, em sua maioria, aqueles vinculados a grupos que ocupam papéis dominantes na sociedade e que, em geral, possuem o domínio da modalidade escrita. Sendo assim, são consideradas práticas letradas e, portanto, associadas ao progresso, apenas aquelas relacionadas às habilidades de ler e escrever. Em decorrência, as sociedades cuja tradição é fortemente baseada na oralidade são consideradas menos desenvolvidas. Vê-se que, nessa perspectiva, o letramento configura-se como o ponto nodal entre a cultura oral e a escrita e, ao mesmo tempo, como a mola propulsora capaz de tornar as sociedades mais modernas.

Com base nas críticas que tece ao modelo autônomo, Street (1984) propõe o modelo ideológico de letramento. Nesse modelo, a oralidade e a escrita são tidas como atividades integradas que estão presentes em múltiplas práticas letradas, cujas necessidades e usos variam de acordo com o contexto. Assim, o modelo 
ideológico de letramento leva em conta a variedade das práticas letradas locais. Tais práticas devem ser estudadas como formas que são de reproduzir ou desafiar as hegemonias presentes na sociedade, ou seja, tendo em vista a dimensão de poder que as constitui. Nesse sentido, o objetivo está além das consequências do letramento, amplia-se para o real significado que as práticas com a língua têm para os grupos que as utilizam.

O cenário linguístico de Timor-Leste permite entrever, portanto, como o status das línguas em contato nesse território atua como mecanismo de valoração de determinadas práticas de linguagem em detrimento de outras. Nesse caso, a relação construída historicamente entre a LP e a modalidade escrita acaba por subsidiar um entendimento que, por vezes, exclui do conceito de letramento a diversidade de práticas que decorrem das interações dos sujeitos com as diferentes línguas.

\section{Presença da palavra escrita em Timor-Leste}

Tendo em vista o contexto sócio-histórico já mencionado, é notável perceber que Timor-Leste iniciou sua história como país autônomo estampando uma carência de textos escritos. Além disso, a inexistência de uma produção editorial em Timor, ${ }^{4}$ durante muito tempo, prejudicou o alcance pela população à literatura produzida por autores timorenses. Por esse motivo, os principais expoentes nacionais, como Luís Cardoso, Fernando Sylvan, João Aparício, Abé Barreto Soares, Xanana Gusmão, para citar alguns, viveram e publicaram suas obras fora de

\footnotetext{
4 A partir deste ponto, utilizaremos o termo Timor como sinônimo de Timor-Leste e empregaremos, no decorrer deste texto, ambas as nomenclaturas, embora saibamos que politicamente Timor se refira à ilha maior que comporta dois territórios: o país independente Timor-Leste e Timor Ocidental, região pertencente à Indonésia. Nossa opção tem o intuito de evitar repetições e manter o texto mais fluido.
} 
Timor na época da ocupação indonésia, "dificultando o acesso aos livros e à leitura e, até, a formação de uma opinião pública informada e esclarecida”. (RAMOS, 2012, p. 156).

Para compreendermos o cenário vivenciado por TimorLeste atualmente, traçamos um breve panorama do sistema educacional e consequente lugar que o livro ocupou e ocupa na história do país. Constatamos, primeiramente, que, até 1880, não havia biblioteca alguma. Em 1885, foi publicado em tétum o catecismo advindo da Igreja Católica. Já em 1898, foi criado o Colégio Jesuíta de Soibada, tornando-se o único estabelecimento de ensino secundário no país. Em 1910, Timor contava com somente nove escolas de ensino primário. O Liceu de Díli surgiu apenas em 1952 e, em 1965, a primeira escola técnica. As séries que correspondem ao ensino médio no Brasil alcançaram o interior do país somente em 1972 (THOMAZ, 2002). Dessa maneira, apesar de lento, o crescimento do sistema educacional alavancou a circulação de livros com mais intensidade, os quais, entretanto, ainda se encontravam em quantidade limitada. No início dos anos 1970, a expansão da imprensa ganha força e se materializa em três relevantes periódicos: Revista Seara, A Província de Timor e a Voz de Timor. (PIRES, 2000 apud DE LUCCA, 2014).

Como mencionamos anteriormente, com a invasão da Indonésia, em 1975, boa parte dos livros e materiais impressos do país foi destruída e queimada. Consideramos esse ato uma representação da condenação dos livros, para que as ideias nacionalistas da então elite timorense e a língua escrita utilizada, o português, fossem banidas.

Com relação aos legados que a ocupação indonésia em Timor deixou na esfera educacional, destacamos a formação 
de uma geração formada em língua indonésia até 1999. Após a Restauração da Independência, testemunhou-se a destruição do grande legado físico: as escolas e seus livros. As destruições dos livros na entrada e na saída do exército indonésio compartilharam pelo menos um objetivo comum: o apagamento de uma história registrada pela escrita.

Até 2003, ano em que foi inaugurada a primeira biblioteca pública em Díli (SCHERL, 2007), não havia bibliotecas públicas no país, somente algumas coleções particulares. Em 2014, existiam duas instituições importantes que ofereciam bibliotecas públicas e acessíveis na capital: o Arquivo \& Museu da Resistência Timorense (AMRT) e o Memorial de Balide. Outras instituições com bibliotecas em Díli, ambas atreladas a Portugal, são o Instituto Camões e a Fundação Oriente. A esses espaços públicos de acesso aos livros podemos adicionar o Xanana Gusmão Reading Room, uma ONG, cuja biblioteca possui acervo quase todo em língua inglesa. Há também outras ONGs cujas bibliotecas com literatura em língua inglesa possuem um lugar de destaque, como a Timor Aid e a Fundação Alola. Com efeito, as bibliotecas já mencionadas constituíam, em 2014, os principais, porém não os únicos, lugares públicos de concentração de livros na capital (DE LUCCA, 2014).

Além dessas já existentes, encontra-se em construção uma Biblioteca Nacional, a qual tem como objetivo "proceder à recolha, tratamento e conservação do património documental timorense, bem como assegurar o seu estudo, divulgação e as condições para a sua fruição e garantir a classificação e inventariação do património bibliográfico nacional”. (TIMORLESTE, 2017). 
Por fim, é notável perceber que preservar a história de Timor por meio de livros sempre foi um obstáculo e que o acesso aos poucos materiais escritos que chegaram ao país foi dificultado. Nesse contexto, a escola se configura como importante - e por vezes único - espaço de acesso que os timorenses têm à palavra escrita.

Na seção seguinte, apresentamos uma discussão acerca do componente "leitura" presente no currículo do ensino básico de Timor-Leste, nível de atuação dos professores participantes deste estudo.

\section{A leitura nas orientações curriculares de Timor-Leste}

A Restauração da Independência de Timor-Leste, em 2002, apresentou diversas problemáticas relacionadas à reestruturação do país. Dentre elas, destacamos o sistema educacional, especificamente o currículo do ensino básico ( $1^{\circ}$ e $2^{\circ}$ ciclos), que acabou sendo desenvolvido e implementado após 2004.

Antes de abordarmos o papel que a leitura ocupa dentro do currículo, esclarecemos que "a leitura é uma competência individual e social, um processo de produção de sentidos que envolve quatro elementos: o leitor, o autor, o texto e o contexto". (COSSON, 2014, p. 36). Reconhecemos, portanto, que é a partir da articulação dos quatro elementos constituintes do ato de ler que a leitura se materializa, em detrimento da ideia de se tomar exclusivamente um desses elementos como central. Acrescentamos a essa concepção o fato de que a leitura do mundo - conhecimentos provenientes de interações sociais precede a leitura da palavra (FREIRE, 2011), principalmente se considerarmos o contexto de uma sociedade de tradição oral. 
Esclarecidos os pressupostos sobre leitura, vale ressaltar que o modelo de aprendizagem do currículo em curso em Timor-Leste, em 2009, foi criticado por Bassarewan e Silvestre (2010) e descrito como uma pragmática canalizada no professor e influenciada por métodos de memorização e de disciplina impositiva. Tais observações se opõem ao discurso oficial, que defendia uma aprendizagem "centrada no aluno", "inclusiva" e "ativa". Mais especificamente com relação à leitura, as autoras reconhecem que é preciso introduzir acesso a níveis mais sofisticados dessa habilidade a partir do trabalho diário do professor com a reflexão e a crítica entre os alunos. No caso de Timor, que é conhecido por manter uma tradição ágrafa e basicamente oral, o conhecimento de mundo da criança timorense, em geral, é aquele transmitido pelos colegas ou pela família, realidade que demanda, portanto, que o trabalho com as demais práticas de linguagem na sala de aula, como a leitura, leve em conta esse conhecimento prévio.

No entanto, o processo de ensino-aprendizagem da leitura, pelo menos até 2014, não estava elaborado sob essa perspectiva, ou seja, as orientações do programa curricular não promoviam o desenvolvimento da leitura reflexiva, mas eram baseadas na leitura mecânica e na decodificação de palavras.

Em 2014, o governo passou a implementar um novo currículo para a educação básica, ${ }^{5}$ tendo como foco maior a devida valorização das línguas maternas dos timorenses (TIMORLESTE, 2014). Uma das justificativas para essa implementação foi a "necessidade de resolver os níveis extremamente baixos de capacidade de leitura" (LA'O HAMUTUK, 2018), resultado de uma pesquisa que apontou o risco de repetição e evasão de

5 De acordo com a Lei de Bases da Educação de Timor-Leste (Lei nº 14/2008, de 29 de outubro), o ensino básico do país é dividido em: $1^{\circ}$ ciclo $\left(1^{\circ}, 2^{\circ}, 3^{\circ}\right.$ e $4^{\circ}$ anos $), 2^{\circ}$ ciclo $\left(5^{\circ}\right.$ e $6^{\circ}$ anos $)$ e $3^{\circ}$ ciclo $\left(7^{\circ}, 8^{\circ}\right.$ e $9^{\circ}$ anos $)$. 
alunos de escolas primárias que não possuíam a habilidade de leitura (BANCO MUNDIAL, 2009). Para tanto, elaboraram um plano de ensino em que a LP é introduzida apenas no $3^{\circ}$ ano escolar, quando os alunos já teriam aprendido as habilidades básicas de literacia ${ }^{6}$ na língua tétum, a saber: (i) ouvir e falar, (ii) ler e (iii) escrever.

Diante do exposto, depreendemos que o processo da leitura se desenvolveu de forma singular em Timor-Leste. As políticas linguísticas resultaram em práticas precárias no desenvolvimento sociocognitivo em gerações de estudantes. Sendo assim, uma sociedade leitora em menor ou maior escala é consequência de vários fatores envolvidos nos processos educacionais de cada contexto. No caso de Timor, o desafio com a leitura pode ser compreendido como reflexo da constante reconstrução de políticas e das efêmeras práticas didáticopedagógicas.

\section{Pressupostos teóricos: a natureza social da linguagem}

$\mathrm{Na}$ tese sustentada por Bakhtin (2011), a natureza da linguagem é social, constitui os sujeitos e é constituída nas interações realizadas por eles. Nessa perspectiva, o entendimento da linguagem, em sua complexidade social, histórica e ideológica, passa, necessariamente, pela observância das relações entre os homens nos contextos de suas atividades sociais e pelo princípio dialógico que a constitui — os encontros entre diferentes posicionamentos axiológicos colocados em confronto na relação com o outro. Nas palavras do autor:

$\overline{6}$ Esse é o termo utilizado em Portugal para se referir a letramento. 
A vida é dialógica por natureza. Viver significa participar do diálogo: interrogar, ouvir, responder, concordar, etc. Nesse diálogo o homem participa inteiro e com toda a vida: com os olhos, os lábios, as mãos, a alma, o espírito, todo o corpo, os atos. Aplica-se totalmente na palavra, e essa palavra entra no tecido dialógico da vida humana, no simpósio universal. (BAKHTIN, 2011, p. 348).

A noção de diálogo, na acepção de Bakhtin, não pode ser compreendida como a mera interação face a face, situada em um tempo histórico e espaço social, pois está além disso. É ligada à corrente ininterrupta da comunicação discursiva, cuja existência é contínua, trazendo à tona sentidos que são ressignificados a cada nova enunciação. O elo nesse grande diálogo é o enunciado concreto - materialização das relações entre os sujeitos sociais. Cada enunciado comporta sentidos que são elaborados pelo que lhe vem do exterior - situação social imediata e meio social mais amplo - e dialoga responsivamente com a palavra do outro. As relações dialógicas que o enunciado estabelece em sua constituição nunca se repetem, pois as condições de produção em que se realizam, inseridas no contínuo movimento histórico e social, configuram-se de maneira insólita. Por conta disso, o enunciado revela-se sempre como novo na cadeia da comunicação discursiva, e a compreensão de sua constituição está, intrinsecamente, ligada aos aspectos do contexto extraverbal de sua produção.

$\mathrm{Na}$ cadeia ininterrupta da comunicação discursiva, conforme Bakhtin (2002), os elementos mobilizados na produção dos enunciados encontram-se em meio ao embate de duas forças veiculadoras de ideologias: as forças centrípetas, que buscam unificar e homogeneizar os enunciados, e as forças centrífugas, que dinamizam, descentralizam o discurso. Como 
resultado da atuação das forças centrípetas, as quais conduzem à sistematicidade e unicidade da língua, tem-se a construção histórica de língua homogênea e monológica (BAKHTIN, 2002). Em contraponto à centralização, atuam as forças centrífugas, que fomentam a diversidade e permitem entrever a multiplicidade de vozes sociais, ou seja, a heterogeneidade da língua. Diz Bakhtin (2002, p. 82): "ao lado das forças centrípetas caminha o trabalho contínuo das forças centrífugas da língua, ao lado da centralização verbo-ideológica e da união caminham ininterruptos os processos de descentralização e desunificação." $\mathrm{Ou}$ seja, em confronto com as forças centrípetas está um conjunto múltiplo e heterogêneo de vozes sociais que coexistem em relação dialógica, constituindo a realidade heterogênea da linguagem - a heteroglossia. Essas vozes configuram-se como representantes das ideologias de grupos sociais específicos em determinados tempos e espaços históricos e atuam, portanto, de modos distintos no processo de construção dos enunciados.

A relação espaço e tempo na produção dos enunciados é explicada por Bakhtin (2002) por meio do conceito de cronotopo. Proposto pelo autor, inicialmente, tendo como base para a reflexão a esfera artístico-literária, o conceito de cronotopo pode ser estendido a outras esferas da organização social, já que estas apresentam contextos específicos decorrentes das relações entre as categorias tempo e espaço. Dessa forma, onde e quando o enunciado é produzido são elementos que estão "fora", mas participam de sua composição. Assim, ao enunciar, o sujeito dialoga (responde ativamente) com outros enunciados, movimento que ocorre a partir de uma posição axiológica situada social e historicamente. 
É com base nesse entendimento amplo de enunciado que analisamos as respostas dadas pelos professores no âmbito deste estudo. Assim, consideramos que as escolhas desses sujeitos, no conjunto de enunciados previamente elaborados como opções de práticas de leitura, configuram uma tomada de posição singular e única, afinal, assim o é cada enunciado, marcado pela expressividade do indivíduo que o constitui e a situação de comunicação, que é sempre nova.

$\mathrm{O}$ olhar que lançamos para os enunciados que expressam as valorações dos professores sobre as práticas de leitura em LP coloca em diálogo os conceitos anteriormente apresentados com o cenário linguístico de Timor-Leste. São trazidos à baila também as concepções e modelos de letramento expressos nesses enunciados, pois, certamente, são elementos subjacentes à construção histórica e social do país e que reverberam nas práticas com leitura que se dão nos ambientes escolares.

\section{Metodologia de pesquisa}

Tendo em vista o exposto anteriormente, conduzimos uma investigação com o intuito de identificar e compreender quais estratégias de leitura em LP professores timorenses valoram positivamente no desenvolvimento de sua prática pedagógica. Para tanto, aplicamos um questionário aos sujeitos da pesquisa e, posteriormente, discutimos os dados com base no aporte teórico aqui utilizado.

Apresentamos, a seguir, os sujeitos envolvidos na pesquisa e o instrumento de coleta de registro utilizado (o questionário). 


\subsection{Participantes da pesquisa e instrumento de geração dos dados}

Os participantes desta pesquisa são 14 docentes atuantes no ensino básico de Timor, licenciados no curso de Formação de Professores do Ensino Básico da Universidade Nacional Timor Lorosa'e (UNTL).

A fim de buscar evidências para o estudo em questão, recorremos ao questionário aplicado virtualmente. Essa escolha se deu tanto pela flexibilização no tempo de resposta como também pela facilidade de contato com os participantes da pesquisa por meio de redes sociais, já que eles vivem em um país muito distante e seria inviável aplicar o questionário pessoalmente. Quanto à tipologia das questões, de um total de 17, havia quatro perguntas protocolares, referentes apenas à identificação dos participantes (nome, gênero, data de nascimento e município em que nasceu), 12 perguntas fechadas, em que o informante escolhe sua resposta entre opções predefinidas, e uma aberta, em que ele é capaz de dar sua opinião livremente. Como o questionário foi aplicado virtualmente, a opção "nome" objetivou identificar os participantes para garantir que uma mesma pessoa não respondesse acidentalmente mais de uma vez e, assim, tivéssemos respostas duplicadas. Apesar de o nome dos participantes ter sido requisitado, mantivemos seu sigilo durante a pesquisa.

O questionário foi dividido em quatro seções. A primeira, já mencionada, visou à identificação dos sujeitos participantes. A segunda, por sua vez, esteve relacionada à experiência com leitura durante o período em que eles estudavam no $3^{\circ}$ ciclo e no Secundário (equivalente ao Fundamental II e Ensino Médio, 
no Brasil). A terceira teve como foco o contato com materiais de leitura que os sujeitos tiveram no período de formação na universidade e têm atualmente. Por fim, a quarta seção, a qual nos interesse a neste trabalho, refere-se à atuação desses professores em sala de aula, isto é, ao nível de importância que eles concedem às práticas de leitura na condição de professores de LP no ciclo básico em Timor-Leste.

\section{Análise dos dados}

Considerando o objetivo deste estudo — identificar e compreender quais estratégias relacionadas à leitura em LP os professores timorenses valoram positivamente no desenvolvimento de sua prática pedagógica - e o aporte teórico-metodológico que aqui utilizamos, faz-se importante, novamente, ressaltar que concebemos as alternativas que figuram como respostas às perguntas presentes no questionário como enunciados que expressam diferentes posicionamentos axiológicos acerca do tema em questão: o ensino da leitura em português nas escolas de Timor-Leste. ${ }^{7}$

O cronotopo, de acordo com Bakhtin (2002), reflete, de maneira direta, as ideologias dos diferentes tempos e espaços na produção dos enunciados. Dessa forma, na análise dos enunciados mais assinalados pelos sujeitos, consideramos os sentidos que lhes são atribuídos no momento de realização da pesquisa e no diálogo com a história que os constitui, movimento de encontro de tempos, pequeno e grande tempo (BAKHTIN, 2011). A inter-

\footnotetext{
7 Reconhecemos a limitação da opção pela análise das respostas dadas em um questionário majoritariamente fechado, já que "esse tipo de questionário limita o respondente às alternativas apresentadas". (CUNHA, 2007, p. 70). Entretanto, para garantir a oportunidade de o participante expressar sua opinião, caso esta não estivesse contemplada nas opções, utilizamos o recurso "outro".
} 
relação do cronotopo com a produção dos enunciados não se dá de maneira evidente, pois, nos diferentes cronotopos em que os enunciados são proferidos, estão presentes vozes sociais. Essas vozes constituem a heteroglossia e configuram-se como representantes das ideologias de grupos sociais específicos em determinados tempos e espaços históricos e atuam, portanto, de modos distintos no processo de construção dos enunciados. Além disso, é importante atentar para as relações de forças presentes na esfera educativa, as forças centrípetas e as forças centrífugas, que atuam na cadeia de comunicação verbal, em favor das ideologias, sejam aquelas tradicionalmente instituídas ou aquelas que veiculam a mudança.

A análise que realizamos dos enunciados mais recorrentemente assinalados pelos professores timorenses, no âmbito deste estudo, leva em conta que esses sujeitos apresentam dificuldades no que diz respeito à proficiência em português (VIEGAS; RAMOS; ANTUNES, 2015), as quais são agravadas quando essa língua se torna para eles objeto de ensino. Esse cronotopo específico influencia, certamente, suas respostas e insere-se em outro cronotopo maior - aquele em que ocorre a reintrodução da LP nas práticas educativas em Timor, com a presença de políticas e orientações curriculares nesse sentido. É na relação dialógica com esse contexto que buscamos compreender os enunciados acerca da prática de leitura em LP valorados positivamente pelos docentes em suas respostas ao questionário.

Como já mencionado, para este estudo, analisamos exclusivamente as respostas das perguntas referentes à quarta seção do questionário aplicado. Na Tabela 1, apresentamos essas perguntas, as respectivas opções de resposta e o quantitativo das respostas selecionadas pelos professores participantes da pesquisa. 


\section{Tabela 1 - Perguntas e opções de resposta do questionário}

Perguntas

Neste ano, você está dando aula para que ciclo?

Qual a sua opinião sobre os alunos timorenses praticarem a leitura em Língua Portuguesa nas escolas?

Em que fase da educação básica você acha que os alunos timorenses estão prontos para ler em Língua Portuguesa?

Quais dessas práticas de leitura você acha que é importante fazer na escola? (Você pode responder mais de uma alternativa)

Na aula de Língua Portuguesa, depois de ler um texto com os seus alunos, que atividade você faz ou faria com eles primeiro?

Se você tivesse que escolher um texto em Língua Portuguesa para que seus alunos leiam na escola, você escolheria um texto de:
Respostas

$\%$

$1^{\mathrm{o}}$ ciclo

38,5

$2^{\circ}$ ciclo

46,2

$3^{\circ}$ ciclo

15,4

Muito importante

84,6

Razoavelmente importante 0

Importante 0

$\begin{array}{ll}\text { Pouco importante } & 7,7\end{array}$

Não é importante $\quad 7,7$

$1^{0}$ ciclo

46,2

$2^{\circ}$ ciclo 38,5

$3^{\circ}$ ciclo 15,4

Secundário 0

Leitura em voz alta pelo professor

53,8

Leitura em voz alta por um aluno

da turma

53,8

Leitura em voz alta em duplas $\quad 61,5$

Leitura em voz alta por todos os alunos

38,5

Leitura individual e silenciosa $\quad 38,5$

Não acho importante a prática de leitura na escola

\section{Estudo do vocabulário}

38,5

Estudo da gramática

Estudo sobre o assunto do texto

Estudo da estrutura do texto

(frases, parágrafos, etc.)

30,8

15,4

Estudo do título do texto $\quad 15,4$

Autores timorenses

69,2

Autores portugueses

46,2

Autores brasileiros

30,8

Outros

Fonte: Elaborado pelas autoras. 
Primeiramente, chamamos atenção para o elevado número de docentes, $84,6 \%$, que consideram "Muito importante" os alunos timorenses praticarem a leitura em LP nas escolas. Compreendemos essas respostas levando em consideração o contexto heteroglóssico de sua produção - e que nos permite identificar as vozes outras que se infiltram no discurso, pois, como afirma Bakhtin (2002, p. 142), os sujeitos se constituem na interação que estabelecem com as vozes sociais presentes na comunicação discursiva: "A evolução ideológica do homem [...] é um processo de escolha e de assimilação das palavras de outrem." Dessa forma, dentre as relações dialógicas que constituem esse enunciado, identificamos marcas de vozes sociais provenientes, sobretudo, de palavras de autoridade presentes na sociedade timorense.

A valorização da prática da leitura em LP expressa pelos professores reforça o papel dessa língua nas práticas de linguagem que mobilizam o uso da escrita - o que deixa à mostra a maneira como a hierarquia linguística engendra mecanismos de valorização dessas práticas no contexto escolar. Tal entendimento está em consonância com as orientações presentes no Currículo Nacional do Ensino Básico do Primeiro e Segundo Ciclos (TIMOR-LESTE, 2014), o qual, conforme apontamos anteriormente, tem, entre seus objetivos, elevar os níveis de leitura historicamente baixos da população timorense. Assim, a valorização da leitura em LP nas escolas expressa concepções que se mostram fundamentais na constituição do ato pedagógico do professor: a necessidade que o docente tem de respaldar sua prática em concepções validadas socialmente, pelo discurso de outros, de instâncias acadêmico-científicas e políticoadministrativas — algo que sabidamente não é exclusividade do contexto timorense. 
O diálogo, no sentido que Bakhtin (2011) atribui ao termo, consiste no estabelecimento de relações não apenas de concordância, mas também de confronto entre enunciados. Assim, ao mesmo tempo em que reafirmam as orientações presentes no atual currículo quanto à importância da prática da leitura nas escolas, ao serem questionados sobre o ciclo em que consideram que os alunos timorenses estão prontos para ler em LP, $46,2 \%$ dos docentes indicaram ser o $1^{\circ}$ ciclo, $38,5 \%$ optaram pelo $2^{\circ}$ ciclo e $15,4 \%$ pelo $3^{\circ}$ ciclo. A opção maior para o $1^{\circ}$ ciclo é conflitante com o que preconiza o Currículo Nacional do Ensino Básico do Primeiro e Segundo Ciclos (TIMORLESTE, 2014), que propõe a utilização e ensino da língua tétum, além das línguas nacionais, caso o professor considere necessário, no $1^{\circ}$ ciclo, sendo o português inserido no $2^{\circ}$ ciclo e vindo a ser língua principal de instrução apenas no $3^{\circ}$ ciclo de ensino.

A opção da metade dos docentes que integram esta pesquisa em considerar o $1^{\circ}$ ciclo como etapa ideal para que os alunos timorenses leiam em LP pode ser compreendida no diálogo que estabelece com o currículo anterior, ${ }^{8}$ que preconizava o ensino bilíngue, em tétum e português, desde o $1^{\circ}$ ano de escolaridade. Além disso, pode ser associada ao lugar que, ao longo da constituição histórica do país, a LP ocupa nessa sociedade: o de língua da expressão escrita. Assim, a opção desses professores pela leitura em LP nas escolas desde o $1^{\circ}$ ciclo deixa à mostra a maneira como o status que essa língua ocupa na sociedade timorense sobrepõe-se, no campo metodológico, à realidade das escolas de Timor-Leste, nas quais os alunos iniciam a vida escolar, na maioria das vezes, sem nenhum conhecimento de português e, ainda, sem proximidade com práticas leitoras.

8 O primeiro currículo para o $1^{\circ}$ e o $2^{\circ}$ ciclos do ensino básico, elaborado na recente República Democrática de Timor-Leste, entrou em vigor em 2007, conforme promulgado no Despacho Ministerial nº 01/2007, do dia 13 de março. 
Como sabemos, na construção de sua atividade docente, o professor parte de um conhecimento teórico-prático. Esse conhecimento é construído nas interações do professor com a realidade circundante e na percepção que ele tem das relações sociais e verbais concretas de que participa - aquelas que se dão na esfera escolar ou em outra esfera da atividade humana. Ou seja, seus atos estão imbricados com os demais atos que constituem a experiência/vivência do sujeito docente. No caso específico dos professores timorenses, podemos pensar essa constituição tendo em vista a recente história de Timor-Leste: marcada pela luta em prol da independência e pela valorização da LP em meio às demais línguas que compõem o cenário linguístico timorense.

Nesse processo, a linguagem, mais especificamente sua materialização em signos linguísticos (língua portuguesa), teve um duplo papel: foi utilizada como símbolo da luta contra o domínio indonésio no país - língua da resistência - e, ao mesmo tempo, instrumento veiculador dessa ideia, já que os líderes do movimento contrário à presença indonésia no país, a elite timorense, utilizavam-na em suas comunicações e na veiculação de seus projetos ideológicos. Os discursos provenientes dessa elite exemplificam o dizer de Bakhtin (2011), para quem coexistem, nas diferentes esferas da atividade humana, vozes que atribuem aos enunciados que produzem o caráter de verdade, ou seja, sua palavra representa uma palavra de autoridade na sociedade. No caso de Timor-Leste, o projeto linguístico de valorização da LP se deu pela utilização da palavra de autoridade, a qual, segundo Bakhtin:

[...] é organicamente ligada ao passado hierárquico. É, por assim dizer, a palavra dos pais. Ela já foi reconhecida no passado. É uma palavra encontrada de antemão. 
Não é preciso selecioná-la entre outras equivalentes. Ela ressoa numa alta esfera, e não na esfera do contato familiar. Sua linguagem é uma linguagem especial (por assim dizer, hierática). (BAKHTIN, 2002, p. 143, grifos do autor).

Vemos, portanto, que os docentes timorenses são perpassados por inúmeras vozes, respondendo e se posicionando de diferentes formas perante elas. Vale destacar que esse diálogo não se restringe àquele que pode vir a se instaurar entre diferentes línguas que coexistem em um território, mas, sim, como vimos, à diversidade de vozes — posições que constituem o discurso que participam da comunicação discursiva.

Assim sendo, a mútua constituição linguagem/sujeitos sociais ocorre em meio a uma arena tensa em que coexiste uma multiplicidade de vozes sociais, em um movimento dialógico em que atuam forças interdependentes: as forças centrípetas e as centrífugas. Trazemos como exemplo desse embate de forças as respostas dadas pelos professores a duas questões: as práticas de leitura que consideram mais importantes para realizar na escola e as atividades que realizam com os alunos após a leitura de um texto. Em relação àquela, 61,5\% dos professores apontaram que consideram a "Leitura em voz alta em duplas" importante, seguido da "Leitura em voz alta pelo professor" e "Leitura em voz alta por um aluno da turma", assinaladas por 53,8\% dos docentes, e, com 38,5\%, a "Leitura em voz alta por todos os alunos". Com esse mesmo quantitativo, 38,5\%, está "Leitura individual e silenciosa". No que diz respeito à outra questão, sobre as atividades que realizam ou realizariam com os alunos após a leitura de um texto: $38,5 \%$ dos professores apontaram o "Estudo do vocabulário", 30,8\%, o "Estudo sobre o assunto do texto", 15,4\%, o "Estudo da estrutura do texto (frases, parágrafos, etc.)" e outros 15,4\%, o "Estudo do título do texto". 
A importância dada pelos docentes à prática de ler em voz alta pode ser relacionada à forte tradição oral presente em TimorLeste, que, como vimos, ocupa, na sociedade timorense, espaço reconhecidamente maior que a palavra escrita, como também essa prática deixa à mostra a importância dada ao reconhecimento do sistema grafofonético, algo que integra, mas não contempla de todo, o conjunto de ferramentas linguísticas necessárias no exercício da leitura (GIBBONS, 2002 apud NATHUVE, 2017). O trabalho com a leitura que parte do reconhecimento do sistema linguístico para então construir significado textual aponta para o processamento assegurado pelo modelo ascendente de leitura (ou bottom up), proposto inicialmente por Gough (1972). Em outras palavras, essa é uma prática centrada na habilidade de decodificar ou transformar em som o que é visto linearmente em um texto, o que faz desse processo um ato mecânico em contraposição ao ato cognitivo, determinado pelo modelo descendente de leitura (ou top-down).

Ainda, a leitura em voz alta preconizada pelos professores remete a práticas presentes nas salas de aula tradicionais, nas quais o professor assume a posição central no processo de ensino - como detentor do conhecimento e, portanto, responsável por protagonizar as ações que visam à "transmissão" desse conhecimento, tradição que permite observar a manifestação das forças centrípetas nesse ambiente. A opção da maioria dos docentes que integram esta pesquisa por essa estratégia metodológica revela que, no ensino da LP — língua com a qual assumidamente possuem dificuldades —, o recurso da leitura em voz alta, que propicia mais a decodificação e correção da pronúncia do que a compreensão daquilo que é lido, configurase, para eles, como um modelo de ensino que reconhecem e que, ao mesmo tempo, sentem-se seguros para realizar. 
Exemplo que consideramos manifestação das forças centrífugas, ou seja, de possibilidades para a inserção de novas práticas nos ambientes educativos timorenses, são as respostas dadas à questão sobre as atividades que os professores dizem fazer após a leitura do texto. Contextualizada à realidade do ensino de português em Timor-Leste - ensino de língua não materna - compreende-se a primeira opção dos docentes ser o "Estudo do vocabulário", opção que vem seguida de "Estudo do assunto do texto". Sobre este, apesar de reconhecermos que a prática realizada sob o signo "estudo do assunto do texto" possa se referir a atividades mais relacionadas à decodificação do que à compreensão (como perguntas cujas respostas exigem apenas a cópia literal de trechos do texto), consideramos que a escolha dos professores por essa opção sinaliza a importância que possam dar, também, à compreensão pelos alunos sobre o conteúdo desse texto.

Além disso, ressaltamos que nenhum professor assinalou a opção "Estudo da gramática" em suas respostas, o que, atrelado às demais respostas a essa questão, nos permite inferir que suas escolhas metodológicas, no que diz respeito ao ensino da leitura, em alguns aspectos, parecem estar mais relacionadas ao plano discursivo da língua (à leitura como diálogo entre textos), do que ao plano estritamente linguístico.

Vemos, portanto, que os enunciados valorados positivamente pelos docentes timorenses no que diz respeito à prática da leitura são decorrentes da influência das forças que continuamente se confrontam na produção dos discursos: as forças centrípetas e as forças centrífugas e, no caso em questão, entre o que é conhecido, historicamente sedimentado, homogeneizador e estabilizador dos discursos da esfera escolar, e o que propõe a abertura para novas práticas. 
Por fim, consideramos importante destacar que $69,2 \%$ dos participantes desta pesquisa afirmaram optar, preferencialmente, por leitura de autores timorenses como prática em sala de aula, seguida de autores portugueses $(46,2 \%)$ e autores brasileiros $(30,8 \%)$. Primeiramente, podemos associar a preferência por autores timorenses à valorização da cultura/línguas de Timor que se encontra muito presente no atual currículo. Os documentos oficiais, mais uma vez, confirmam a ideia de que as vozes de autoridade presentes na sociedade constituem os discursos da população, sobretudo de profissionais atuantes na educação.

Já a escolha, em segunda instância, de atividades de leitura com autores portugueses remete à ideia de que os professores consideram Portugal como berço da LP e, portanto, da literatura nessa língua, e à atual presença dominante de portugueses na esfera educativa timorense. A baixa porcentagem de respostas referentes à preferência por autores brasileiros deve-se, inferimos, ao pouco conhecimento que os professores timorenses têm da literatura brasileira, assim como das luso-africanas, as quais nem são mencionadas nas respostas (já que havia a opção "outro" disponível).

\section{Considerações finais}

Considerando o conturbado contexto sócio-histórico e por se tratar de um país relativamente recente, é indiscutível que TimorLeste tem encontrado, desde seu início, adversidades em seu processo de (re)construção. Notadamente na esfera educacional, o problema se agrava se pensarmos as questões linguísticas que por lá resistem. De um lado, temos o português figurando como língua oficial e de instrução, junto ao tétum, e, de outro, as 
inúmeras línguas maternas coabitando, sobretudo oralmente, em todos os espaços sociais do território. Em meio a esse panorama multilíngue, professores do ensino básico lidam diariamente com dificuldades concernentes ao desenvolvimento de práticas pedagógicas com a LP em sala de aula. Do conjunto de práticas que se realizam nesse ambiente destacamos, no âmbito deste estudo, a leitura - habilidade que, por um conjunto de fatores que fazem parte da constituição desse país, foi historicamente pouco estimulada.

Tendo em vista esse contexto, nesta pesquisa, objetivamos, por meio de enunciados de professores timorenses, identificar as práticas de leitura valoradas positivamente por esses sujeitos no ambiente escolar e compreender, com base na teoria bakhtiniana, os elementos envolvidos na construção desses enunciados. A análise que realizamos nos permite depreender, de modo geral, que aquilo que esses docentes reconhecem e valoram positivamente como ensino da leitura em suas aulas é resultado das relações dialógicas que esses sujeitos estabelecem com os demais enunciados que compõem seu horizonte axiológico, como os discursos provenientes de documentos oficiais que legitimam e orientam o ensino da LP no país (atuação das forças centrípetas) e o contexto heteroglóssico em que estão inseridos (manifestação das forças centrífugas).

Ressaltamos, nesse grande diálogo, a forte atuação das forças centrípetas nos enunciados analisados nesta pesquisa, sobretudo na legitimação e valorização da presença da leitura em LP na prática educativa - discurso que se mostra em consonância com a hierarquização linguística presente no país e no papel que as práticas orais e escritas ocupam nesse cenário. No campo metodológico, a prática da leitura em voz alta orientada 
pelo professor mostrou-se como recurso valorado positivamente, o que demonstra, a nosso ver, que os professores recorrem a práticas que reconhecem e que são capazes de desempenhar no intuito de responder às exigências sociais que estão atreladas à sua profissão, no caso em questão, ao ensino da LP.

A manifestação das forças centrífugas (que sinalizam a abertura para mudanças) foi-nos possível observar, principalmente, nos enunciados voltados aos processos que os professores valoram como atividades pós-leitura de textos. Nestes, verificamos certa prioridade dada à compreensão dos textos em detrimento da mera decodificação do texto escrito baseada em práticas que priorizam o ensino da estrutura da língua - expressão das forças centrípetas no que diz respeito à metodologia de ensino da LP.

Por fim, consideramos pertinente destacar que, nos limites desta pesquisa - na qual contamos com 14 professores atuantes nas escolas de Timor-Leste - , foi possível observar que esses sujeitos, no intuito de atender às exigências institucionais e sociais de sua profissão, ratificam a presença e a importância da prática da leitura em português em suas aulas. No campo metodológico, suas escolhas permitem entrever a valorização de práticas cristalizadas e revestidas de reconhecimento no ambiente educativo, as quais conferem à própria atuação docente esse reconhecimento, e daquelas que sinalizam o diálogo entre textos, ou seja, a maneira pela qual sujeitos e linguagem se constituem mutuamente. 
Referências

ALBUQUERQUE, Davi Borges. Esboço gramatical do Tetun Prasa: língua oficial de Timor-Leste. 2011. 194 f. Dissertação (Mestrado em Linguística) - Universidade de Brasília, Brasília, 2011.

BAKHTIN, Mikhail. Estética da criação verbal. 6. ed. Tradução Paulo Bezerra. São Paulo: Martins Fontes, 2011.

BAKHTIN, Mikhail. O discurso no romance. In: BAKHTIN, Mikhail. Questões de literatura e de estética. 5. ed. São Paulo: Hucitec/Annablume, 2002. p. 71-164.

BANCO MUNDIAL. Timor-Leste: an analysis of early grade reading acquisition, 2009. Disponível em: $<$ http://documents 1. worldbank.org/curated/en/210411468117254153/pdf/569090W P0Timor1Box353744B01PUBLIC11.pdf $>$. Acesso em: $24 \mathrm{fev}$. 2021.

BASSAREWAN, Aicha Binte U.; SILVESTRE, Simone M. $\mathrm{O}$ ensino e a aprendizagem da leitura nos primeiros anos da escolaridade em Timor-Leste. Educação e Pesquisa, São Paulo, v. 36, n. 2, p. 491-504, 2010.

BRITO, Regina Helena Pires. Temas para a compreensão do atual quadro linguístico de Timor-Leste. Ciências \& Letras, Porto Alegre, n. 48, p. 175-194, jul./dez. 2010.

CARVALHO, Manoel Belo de. Formação de professores em Timor-Leste: contributos para a construção de um modelo de formação inicial e contínua. 2007. 111 f. Dissertação (Mestrado em Educação) - Universidade do Minho, Braga, 2007.

COSSON, Rildo. Círculos de leitura e letramento literário. São Paulo: Contexto, 2014.

CUNHA, Maria Jandyra Cavalcanti. Pesquisa Aplicada na área de português para falantes de outras línguas: procedimentos 
metodológicos. In: ALMEIDA FILHO, José Carlos Paes de; CUNHA, Maria Jandyra Cavalcanti. Projetos iniciais em português para falantes de outras línguas. Brasília: EdUnB, 2007. p. 57-85.

DE LUCCA, Daniel. Notas sobre a circulação de livros em Díli, Timor-Leste: letras, lugares e cultura material. In: III SEMINÁRIO DE PESQUISA DA FESP-SP. São Paulo: Fundação Escola de Sociologia e Política de São Paulo, 2014. v. 3, p. 1-25.

FREIRE, Paulo. A importância do ato de ler. São Paulo: Cortez, 2011. (Coleção questões da nossa época, v. 22).

GOUGH, P. B. One second of reading. In: KAVANAGH, J. F.; MATTINGLY, I. G. (org.). Language by ear and by eye. Cambridge: MIT Press,1972. p. 353-378.

HULL, G. A questão da língua em Timor Leste - facto ou fantasia? Janus online, Lisboa, n. 2, 2002. Disponível em: $<$ https://www.janusonline.pt/arquivo/2002/2002_2_3.html $>$. Acesso em: 11 abr. 2019.

LA'O HAMUTUK. O Currículo Nacional para o Pré-Escolar e para o $1^{\circ}$ e $2^{\circ}$ Ciclo do Ensino Básico. La'o Hamutuk: TimorLeste Institute for Development Monitoring and Analysis. Dili, 2018. Disponível em: <https://www.laohamutuk.org/ educ/18CurriculumPt.htm>. Acesso em: 29 nov. 2018.

NATHUVE, Diocleciano. Breves notas sobre a leitura em PLE: aspectos fonéticos. Revista X, [s. l.], v. 12, n. 2, 2017. Disponível em: $\quad<$ https://revistas.ufpr.br/revistax/article/view/48852>. Acesso em: 18 fev. 2021.

PAULINO, Vicente. Céu, terra e riqueza na mitologia timorense. Revista Veritas, Díli, n.1, p. 103-129, 2013.

RAMOS, Ana Margarida. Literatura timorense: da emergência à legitimação. Caderno Seminal Digital, Rio de Janeiro, n. 18, p. 149-160, 2012. 
Práticas de leitura no ensino de Língua Portuguesa em Timor-Leste: um estudo exploratório

SCHERL, Ilana. Desafios e lições aprendidas na implementação de um programa de educação de adultos em Timor-Leste. In: SILVA, K.; SIMIÃO, D. Timor-Leste por trás do palco cooperação internacional e a dialética da formação do Estado. Belo Horizonte: Humanitas/UFMG, 2007. p. 255-272.

STREET, Brian V. Literacy in theory and practice. Cambridge: Cambridge University Press, 1984.

THOMAZ, Luis Felipe F. R. Babel Loro-Sae: o problema linguístico de Timor-Leste. Lisboa: Instituto Camões, 2002.

TIMOR-LESTE. Currículo Nacional do Ensino Básico do Primeiro e Segundo Ciclos. Díli: Ministério da Educação de Timor-Leste, 2014.

TIMOR-LESTE. Decreto-lei no 1/2004, de 14 de abril de 2004. O Padrão Ortográfico da Língua Tétum. Disponível em: $<$ http:// www.mj.gov.tl/jornal/?q=node/1070>. Acesso em: 18 abr. 2021. TIMOR-LESTE. Despacho Ministerial no 01/2007. Ministério de Educação e da Cultura de Timor-Leste, 2007. Disponível em: $<$ http://www.mj.gov.tl/jornal/public/docs/2007/serie_2/serie2 no6.pdf>. Acesso em: 10 nov. 2019.

TIMOR-LESTE. Lançamento da primeira pedra da Biblioteca Nacional de Timor-Leste. Díli: Ministro de Estado e da Presidência do Conselho de Ministros e Porta-voz oficial do Governo de Timor-Leste, 2017. Disponível em: $<$ http://timorleste.gov.tl/? $\mathrm{p}=18626 \&$ print=1\&lang=pt $>$. Acesso em: 16 abr. 2021.

TIMOR-LESTE. Ministério de Educação de Timor-Leste. Lei $\mathbf{n}^{\mathbf{0}} \mathbf{1 4 / 2 0 0 8}$, de 29 de outubro de 2008. Estabelece bases para a educação nacional. Díli: ME, 2008.

VIEGAS, Edmundo; RAMOS, Rui; ANTUNES, Ricardo. Avaliação da proficiência em língua portuguesa dos docentes da Universidade Nacional Timor Lorosa'e, Timor-Leste. Indagatio Didactica, [s. l.], v. 7, n. 2, p. 58-82, out. 2015. 